\title{
Enhancement of Cleanliness and Deposition Rate by Understanding the Multiple Roles of the Showerhead Electrode in a Capacitively Coupled Plasma Reactor
}

\author{
Ho Jun Kim
}

check for updates

Citation: Kim, H.J. Enhancement of Cleanliness and Deposition Rate by Understanding the Multiple Roles of the Showerhead Electrode in a

Capacitively Coupled Plasma Reactor Coatings 2021, 11, 999. https:/ / doi.org/10.3390/coatings11080999

Academic Editor: Alessandro Patelli

Received: 1 August 2021

Accepted: 18 August 2021

Published: 21 August 2021

Publisher's Note: MDPI stays neutral with regard to jurisdictional claims in published maps and institutional affiliations.

Copyright: (C) 2021 by the author. Licensee MDPI, Basel, Switzerland. This article is an open access article distributed under the terms and conditions of the Creative Commons Attribution (CC BY) license (https:// creativecommons.org/licenses/by/ $4.0 /)$.
Department of Mechanical Engineering, Gachon University, 1342, Seongnam-daero, Sujeong-gu, Seongnam-si 13120, Gyeonggi-do, Korea; hojunkim@gachon.ac.kr or tiger.anima@gmail.com

\begin{abstract}
Increasing the productivity of a showerhead-type capacitively coupled plasma (CCP) reactor requires an in-depth understanding of various physical phenomena related to the showerhead, which is not only responsible for gas distribution, but also acts as the electrode. Thus, we investigated how to enhance the cleanliness and deposition rate by studying the multiple roles of the showerhead electrode in a CCP reactor. We analyzed the gas transport in a three-dimensional complex geometry, and the $\mathrm{SiH}_{4} / \mathrm{He}$ discharges were simulated in a two-dimensional simplified geometry. The process volume was installed between the showerhead electrode (radio frequency powered) and the heater electrode (grounded). Our aim of research was to determine the extent to which the heated showerhead contributed to increasing the deposition rate and to reducing the size of the large particles generated during processing. The temperature of the showerhead was increased to experimentally measure the number of particles transported onto the heater to demonstrate the effects thereof on the decrease in contamination. The number of particles larger than $45 \mathrm{~nm}$ decreased by approximately $93 \%$ when the showerhead temperature increased from 373 to $553 \mathrm{~K}$.
\end{abstract}

Keywords: showerhead electrode; capacitively coupled plasma; plasma enhanced chemical vapor deposition; computational fluid dynamics; gas transport; fluid simulation; hydrogenated amorphous silicon

\section{Introduction}

In the semiconductor industry, the thin film processes that are used to deposit various functional layers have been posed many technical challenges [1]. Plasma-enhanced chemical vapor deposition (PECVD) has been chosen as a mainstream deposition method in recent applications because of its wide applicability and technical flexibility [2]. The fabrication of devices currently demands well-designed and highly expensive reactors; however, the acquisition of state-of-the-art PECVD reactors has had serious financial consequences for chip manufacturers. Therefore, chip manufacturers have continuously targeted high production efficiency [3-5]. Towards this objective, showerhead-type capacitively coupled plasma (CCP) PECVD reactors operated in the torr regime are often considered the best configuration for performing challenging processes [6-8]. This is because these reactors have the ability to deposit films with specified properties and with high uniformity. Enhancing the productivity of a showerhead-type CCP-PECVD reactor requires an understanding of the various physical and chemical phenomena induced by the showerhead electrode from the viewpoint of high cleanliness and a high deposition rate.

Based on the above-mentioned need for productivity enhancement, the deposition rate can be increased by adding a high mole fraction of reactive gases to the inlet gas mixture. However, a higher mole fraction of the reactive gas can also accelerate the generation of large particles $\left(r_{p}>1.0 \times 10^{-6} \mathrm{~m}\right.$, where $r_{p}$ is the particle radius $)$ in the homogeneous gas phase nucleation [9]. Importantly, resolving these complex problems related to the cleanliness and the deposition rate requires an understanding of the various 
physical phenomena related to the showerhead electrode. This importance is ascribed to the showerhead electrode not only being responsible for gas distribution (being installed between the gas line and the process volume), but also forming the electrode in a CCP reactor. In addition, for gases that undergo irreversible reaction in PECVD, the uniform distribution of these gases injected through the showerhead electrode and their reaction products are as important for uniform process results as uniform plasma.

In a plasma-processing reactor, the temperature of the reactor is often considered an important factor that could be adjusted to optimize the process. For instance, the temperature of the wafer pedestal should be finely modulated to heat wafers to the targeted temperatures during the manufacturing process [10-13]. Similarly, the temperature of the showerhead electrode should also be tightly controlled during the process. Because the density of the gas mixture is governed by the ideal gas law, the volume of the gas mixture expands rapidly near the hotter parts of the reactor. Thus, the heated showerhead electrode can induce a local decrease in the density of the gas mixture near the corresponding sheath. Therefore, the spatial distributions of the plasma variables such as the ionization rate, excitation rate, and dissociation rate can be optimized by heating the showerhead electrode.

The above-mentioned points motivated this study: we conducted numerical investigations of the effects of the heated showerhead electrode on the spatial distributions of the plasma variables inside a CCP deposition reactor. Despite its importance, it was difficult to find previous research results relating to PECVD with the relevant details. Therefore, we analyzed the gas transport in a three-dimensional complex geometry, and simulated the $\mathrm{SiH}_{4} / \mathrm{He}$ discharges in a two-dimensional simplified geometry. As a case study for PECVD, we used $\mathrm{SiH}_{4} / \mathrm{He}$-based $\mathrm{CCP}$ discharges to deposit a hydrogenated amorphous silicon (a-Si:H) film. The numerical results were validated by comparing them with practical PECVD experimental data. The ability to lower the number of particles deposited on the reactor surface by increasing the temperature of the showerhead was investigated by conducting experimental measurements to determine the number of particles that were deposited on the targeted surface inside the reactor.

\section{Materials and Methods}

A self-consistent model for a CCP deposition reactor was built by considering four major physical phenomena: gas flows, thermal energy balances, gas phase and surface phase reactions, and low temperature plasma discharges. Details of their numerical models are skipped here because they are explained in detail in our previous reports [14,15]. Selected descriptions are included here because of their importance.

\subsection{Mathematical Model for the CCP Discharges}

Based on a drift-diffusion approximation, we consider the continuity in the electron density by solving below:

$$
\begin{gathered}
\frac{\partial n_{e}}{\partial t}+\nabla \cdot J_{e}=S_{e} \\
J_{e}=-D_{e} \nabla n_{e}+\mu_{e} n_{e} \nabla \phi
\end{gathered}
$$

Here, $n_{e}$ is the electron density, $J_{e}$ is the electron flux, $S_{e}$ is the source of the electrons, $D_{e}$ is the electron diffusion coefficient, $\mu_{e}$ is the electron mobility, and $\phi$ is the electric potential.

\subsection{Mathematical Model for the Chemical Reactions}

Near the heated surface, $\mathrm{SiH}_{4}$ can decompose into $\mathrm{SiH}_{2}$ and $\mathrm{H}_{2}$, and similarly, $\mathrm{Si}_{2} \mathrm{H}_{6}$ also can decompose into $\mathrm{SiH}_{4}$ and $\mathrm{SiH}_{2}$ [16,17]. This decomposition initiates a series of gas phase reactions, which generate important silicon-containing products. These siliconcontaining species transport to the surface and react there to become a silicon surface. In this study, the reversible gas phase reactions that are involved are listed below:

$$
\mathrm{SiH}_{4} \leftrightarrow \mathrm{SiH}_{2}+\mathrm{H}_{2}
$$




$$
\begin{aligned}
\mathrm{SiH}_{4} & \leftrightarrow \mathrm{SiH}_{3}+\mathrm{H} \\
\mathrm{Si}_{2} \mathrm{H}_{6} & \leftrightarrow \mathrm{SiH}_{4}+\mathrm{SiH}_{2}
\end{aligned}
$$

One can write reactions (3)-(5) as shown below:

$$
\sum_{\text {reactants }} v^{\prime}{ }_{i k} A_{i} \underset{k_{k, b}^{g}}{\stackrel{k_{k, f}^{g}}{\rightleftarrows}} v^{\prime}{ }_{i k} A_{i} \sum_{\text {products }} v^{\prime \prime}{ }_{i k} A_{i}
$$

Here, $A_{i}$ are the gaseous species, $k_{k, f}^{g}$ is the rate constant of the forward reaction $k$, $k_{k, b}^{g}$ is the rate constant of the reverse reaction, $v_{i k}^{\prime}$ is the forward stoichiometric coefficient for species $i$ in reaction $k$, and $v^{\prime \prime}{ }_{i k}$ is the reverse stoichiometric coefficient for species $i$ in reaction $k$. The net stoichiometric coefficients are defined as $v_{i k}=v^{\prime \prime}{ }_{i k}-v^{\prime}{ }_{i k}$. One can write the net reaction rate for reaction $k$ as shown below:

$$
\begin{gathered}
R_{k}^{g}=R_{k, f}^{g}-R_{k, b}^{g}=k_{k, f}^{g} \prod_{\text {reactants }}\left(\frac{p_{g} f_{i}}{R T_{g}}\right)^{v^{\prime} i k}-k_{k, b}^{g} \prod_{\text {products }}\left(\frac{p_{g} f_{i}}{R T_{g}}\right)^{v^{\prime \prime} i k} \\
k_{k, f}^{g}\left(T_{g}\right)=A_{k} T_{g}^{\beta_{k}} \exp \left(-\frac{E_{k}}{R T_{g}}\right) \\
k_{k, b}^{g}\left(T_{g}\right)=\frac{k_{k, f}^{g}\left(T_{g}\right)}{K_{e q, k}^{g}\left(T_{g}\right)}\left(\frac{R T_{g}}{P^{0}}\right)^{\sum_{i}^{N} v_{i k}} \\
K_{e q, k}^{g}\left(T_{g}\right)=\exp \left(-\frac{\Delta H_{k}^{0}\left(T_{g}\right)-T_{g} \Delta S_{k}^{0}\left(T_{g}\right)}{R T_{g}}\right) \\
\Delta H_{k}^{0}\left(T_{g}\right)=\sum_{i=1}^{N} v_{i k} H_{i}^{0}\left(T_{g}\right) \\
\Delta S_{k}^{0}\left(T_{g}\right)=\sum_{i=1}^{N} v_{i k} S_{i}^{0}\left(T_{g}\right)
\end{gathered}
$$

Here, $A_{k}$ is the pre-exponential factor of reaction $k, \beta_{k}$ is the temperature exponent of reaction $k, E_{k}$ is the activation energy of reaction $k, P^{0}$ is the reference pressure, $H_{i}^{0}$ is the formation enthalpy, and $S_{i}^{0}$ is the entropy.

\subsection{Computational Method}

In this study, we used CFD-ACE+ software [18]. In various previous studies, using CFD-ACE+, discharge cases were successfully simulated [19-21]. Since applying accurate gas flow information to discharge simulations is critical, the non-isothermal flow simulation results from CFD-ACE+ were validated through comparison with the simulation results from the in-house spectral element method code [22]. We used the control volume-based method to discretize the governing equations in this study.

The Scharfetter-Gummel exponential scheme was adopted in both the electron and electron energy conservation equations [18]. We calculated both the electron transport coefficients and the electron impact reaction rates for the $\mathrm{SiH}_{4} / \mathrm{He} \mathrm{CCP}$ discharges. In this study, the 0D Boltzmann equation was solved for the electron energy distribution function. Solving the $0 \mathrm{D}$ Boltzmann equation acts as a preprocessor step that produces a lookup table. The lookup table was used in the CCP discharges simulations.

\subsection{Reactor Geometry and Problem Settings}

Figure 1 shows the discharge volume of our reactor. Because of the axisymmetric geometry, it is possible to analyze our CCP reactor on the $r-z$ plane, where $r$ is the radial coordinate and $z$ is the axial coordinate. The showerhead (upper electrode) is temperature- 
controlled and powered by radio frequency (RF; $13.56 \mathrm{MHz}$ ). The heater (lower electrode) is also temperature-controlled, but grounded. As the process result is often optimized by heating the lower grounded electrode to a sufficient degree (e.g., $T_{h}>500 \mathrm{~K}$ ), it is referred to as the heater. The top-powered electrode, which also delivers the source gas, is known as the gas distribution assembly and normally consists of multiple perforated plates. As depicted in Figure 1, the first plate is the blocker plate, and the second is the showerhead. The gas distribution assembly communicates directly with the plasma region and, consequently, uniformly distributes the reactive gases over the heater surface. When the plasma distribution is uniform, the gas distribution must also be uniform to ensure the surface flux on the heater is uniform. Note that based on a previous experimental study, the holes in the showerhead are shaped into a converging-diverging nozzle to enhance the gas distribution uniformity [23]. To understand the fluid dynamics effects related to a showerhead hole, the gas flows passing through showerhead holes were computationally simulated, and distributions of the gas velocity magnitudes were extensively analyzed for Case 1. Details of Case 1 are discussed later.

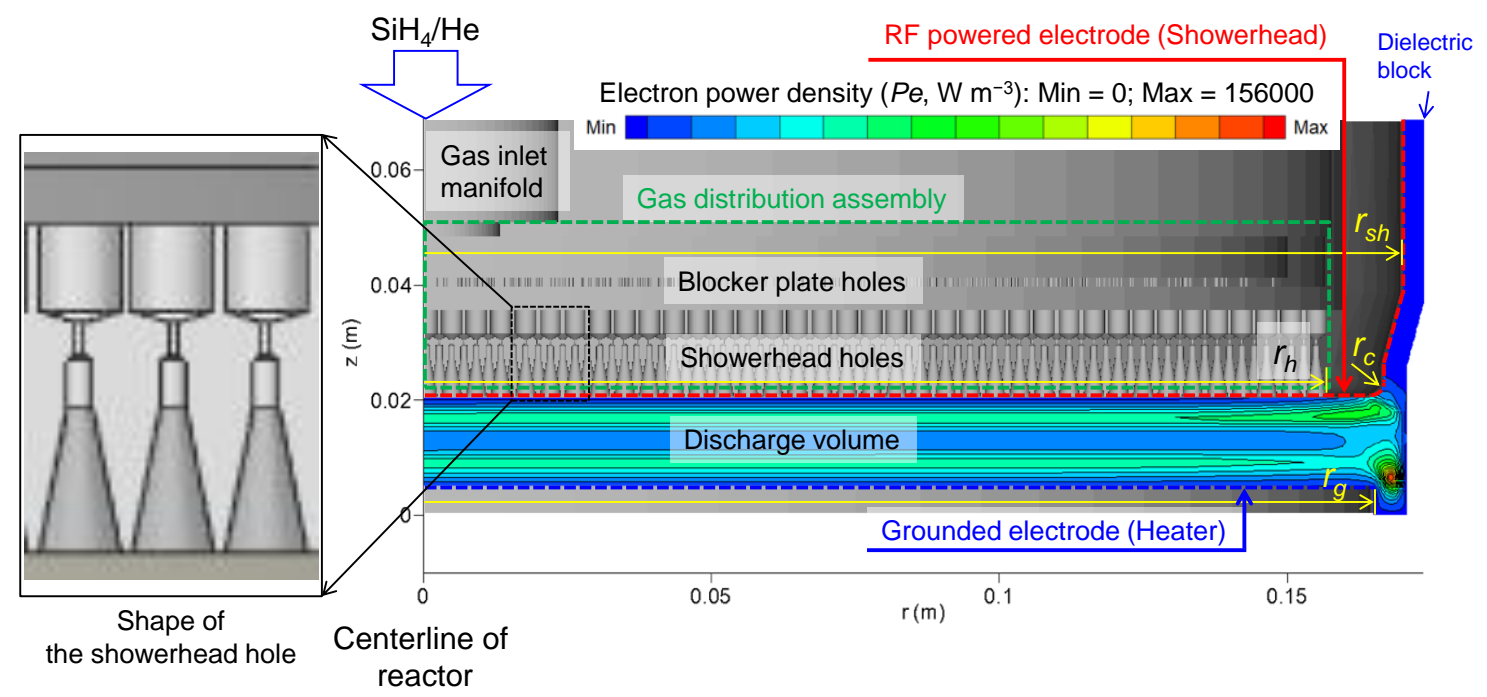

Figure 1. CCP reactor configuration is depicted with the reactor dimensions. The spatial variation in the electron power density $\left(P_{e}, \mathrm{~W} \mathrm{~m}^{-3}\right)$ is superimposed. The inset shows the shape of the showerhead hole.

Note that the gas transport simulation was conducted using three-dimensional complex geometry (i.e., the simulation mimicked the real reactor geometry; see Figure 1), whereas for the CCP simulations, a simplified, more computationally friendly, two-dimensional geometry was used to lower the computational cost. For the CCP discharge simulations, we simply assumed that the $\mathrm{SiH}_{4} / \mathrm{He}$ mixtures are provided through an inlet boundary of the process volume, which corresponds to the outlet of the gas distribution assembly in a radially uniform manner, instead of passing through a series of showerhead holes. As the showerhead temperature was controlled by the heating module (Ohmic heating), the gas temperature and density were sufficiently radially uniform along the showerhead radius. Despite the inlet gas being accelerated inside the showerhead hole, the non-uniformities of the gas temperature and density were less than $3 \%$ with $T_{s h}=373 \mathrm{~K}\left(T_{s h}=\right.$ the showerhead temperature) and less than $6 \%$ with $T_{s h}=473 \mathrm{~K}$ in the simulation results of the threedimensional gas flow.

The input conditions in the considered cases are listed in Table 1. As indicated in the table, for all cases, the sidewall temperature $\left(T_{s w}\right)$ and the heater temperature $\left(T_{h}\right)$ were commonly set to 423 and $673 \mathrm{~K}$, respectively. To observe the effects of the showerhead temperature $\left(T_{s h}\right)$ on the CCP discharges, in Cases 2, 3, 4 and 5, the showerhead temperatures $\left(T_{\text {sh }}\right)$ were set to $373,423,473$, and $673 \mathrm{~K}$, respectively. The following input conditions were specified for all cases: the $\mathrm{SiH}_{4}$ flow rate was set to $50 \mathrm{sccm}$, the He flow 
rate was set to $5000 \mathrm{sccm}$, the gas pressure was set to $400 \mathrm{~Pa}$, and the input power for the $\mathrm{RF}$ discharge was set to $100 \mathrm{~W}$.

Table 1. List of cases considered in this study. Case 1 was considered in a three-dimensional geometry.

\begin{tabular}{clcc}
\hline Case No. & $\begin{array}{c}\text { Considered } \\
\text { Physics }\end{array}$ & $\begin{array}{c}\text { Considered } \\
\text { Geometry }\end{array}$ & $\begin{array}{c}\text { Showerhead Temperature } \\
\left(\mathbf{T}_{\boldsymbol{s h}}, \mathbf{K}\right)\end{array}$ \\
\hline 1 & Gas flows only & 3D complex geometry & 473 \\
2 & Gas flows + Plasma discharges & 2D simplified geometry & 373 \\
3 & Gas flows + Plasma discharges & 2D simplified geometry & 423 \\
4 & Gas flows + Plasma discharges & 2D simplified geometry & 473 \\
5 & Gas flows + Plasma discharges & 2D simplified geometry & 673 \\
6 & Gas flows + Plasma discharges & 2D simplified geometry & Modified inlet (3D) \\
\hline
\end{tabular}

Note that the contour in Figure 1 depicts the spatial distribution of the electron power density $\left(P_{e}\right)$ for Case 2 . The off-axis maximum of the electron power density $\left(P_{e o}=1.56 \times 10^{5} \mathrm{~W} \mathrm{~m}^{-3}\right)$ occurs just beside the heater edge.

\subsection{Experimental Details}

We used an ellipsometer (SFX-200, KLA Tencor, Milpitas, CA, United States) and an X-ray diffractometer (SmartLab, Rigaku corporation, Tokyo, Japan) to measure the properties of the a-Si:H layer experimentally [24]. We measured the film densities of the a-Si:H layer $\left(\rho_{S i}\right)$ experimentally, and these densities were used to estimate the deposition rates in the simulations. At the heater temperature of $673 \mathrm{~K}, \rho_{S i}$ was $2.32 \mathrm{~g} \mathrm{~cm}^{-3}$. The film thicknesses were measured with the ellipsometer. To simulate the surface depositions, the surface fluxes of silicon-containing radicals $\left(\mathrm{Si}_{x} \mathrm{H}_{y}\right)$ were used to develop a sticking model, following the approach in previous studies $[14,15]$. The sticking coefficients of the radicals were adopted from other groups' experimental data $[25,26]$. The experimental setup and methodology were described in detail in our previous reports [14,15].

\section{Results and Discussion}

\subsection{Analysis of Gas Flows in a Three-Dimensional Geometry}

In this section, we describe the simulation of the $\mathrm{SiH}_{4} / \mathrm{He} \mathrm{CCP}$. The simulation was designed to analyze the extent to which the heated showerhead contributes to increasing the deposition rate and to lowering the number of particles generated during plasma processes.

First, we simulated gas flows in a three-dimensional complex geometry. For Case 1, Figure 2a shows the flow streamlines, which are the directions in which the gas fluid flows, and Figure $2 b$ shows the distribution of the magnitude of the gas velocity. Note that the highly accelerated gases are fed through a center-positioned narrow gas line (i.e., the gas inlet manifold in Figure 1). The inlet gases flow fast: the Reynolds number $(\operatorname{Re}=\rho U L / \mu$, where $\rho$ is the density, $U$ is the characteristic velocity, $L$ is the characteristic length, and $\mu$ is the dynamic viscosity) is high. The combined use of the blocker plate and the showerhead induces the suppression of a tangled gas flow structure, which is observed when a large amount of gas is supplied via the inlet and forced to rotate owing to both the inertia of motion and an abrupt change in the flow direction. 
(a)

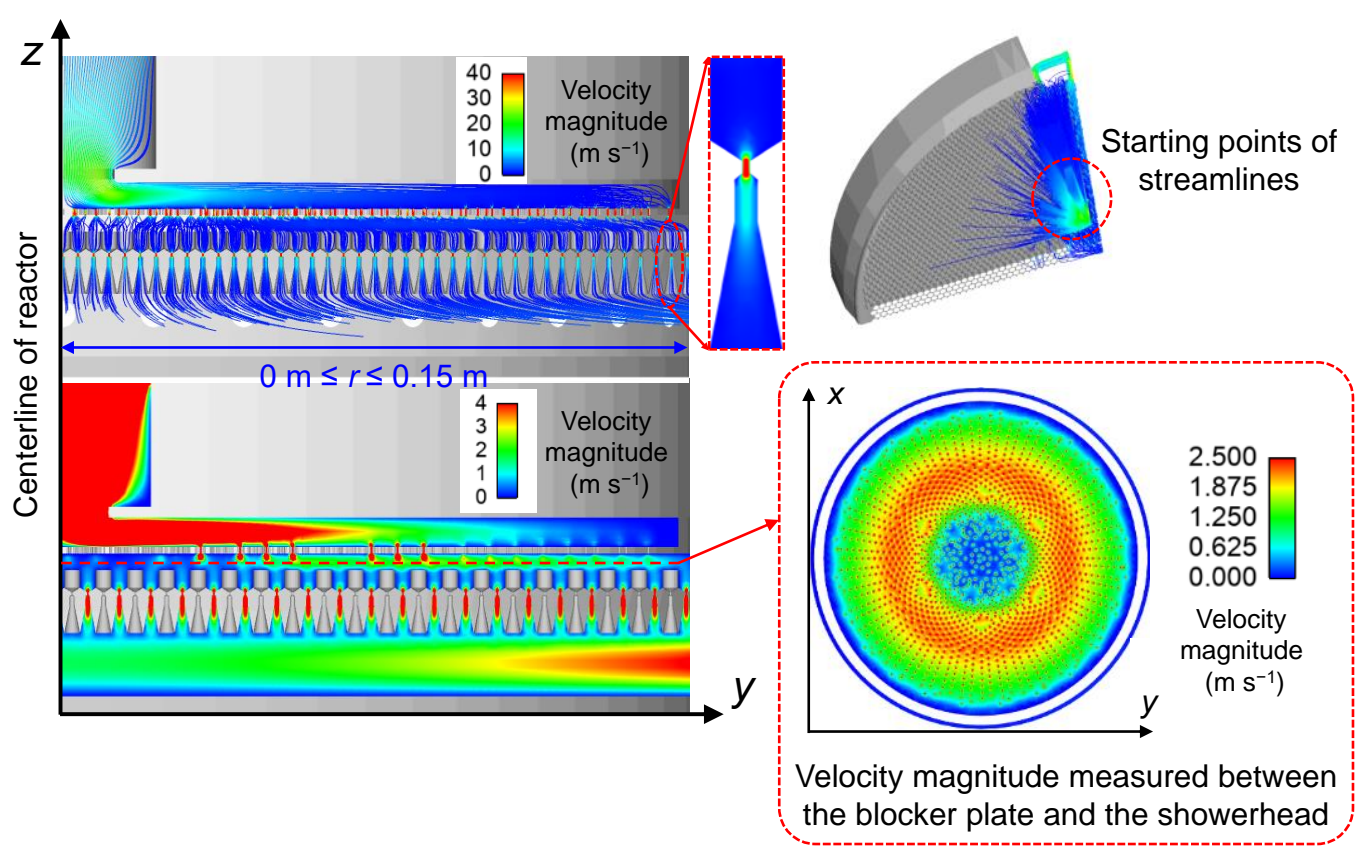

Figure 2. The 3D gas flow simulation results for Case 1: (a) streamlines and (b) gas velocity magnitude contour plot.

\subsection{Effects of the Heated Showerhead on Source Density Distributions}

Kim and Lee stated that the application of the appropriate inlet boundary conditions can be critical to precisely determining the plasma and radical distributions in a CCP deposition reactor [21]. Similarly, Sansonnens et al. attempted to determine how film uniformity can be achieved in a showerhead-type CCP reactor using a simple one-dimensional model [6]. They proposed the following equations:

$$
\begin{gathered}
\frac{d}{d x}\left(n_{A} v(x)\right)=D_{A} \frac{d^{2} n_{A}}{d x^{2}}+S(x)-k_{d} n_{e} n_{A} \\
\frac{d}{d x}\left(n_{B} v(x)\right)=D_{B} \frac{d^{2} n_{B}}{d x^{2}}+k_{d} n_{e} n_{A}-k_{s} n_{B} \\
\frac{d}{d x}\left(n_{C} v(x)\right)=D_{C} \frac{d^{2} n_{C}}{d x^{2}}+k_{d} n_{e} n_{A}
\end{gathered}
$$

where $x$ is the spatial coordinate; $k_{d}$ is the electron impact dissociation rate; $n_{i}(i=A, B$, or $C$ ) is the density of species $i$; $D_{i}$ is the diffusivity of species $i$; $S(x)$ represents the spatial source term of ingredient mixture gas $(A) ; v(x)$ is defined as the gas velocity averaged over the electrode spacing; $A$ is dissociated by the electron impact reaction (with $k_{d}$ ) to generate $B$ and $C$, which are reactive radicals; and $B$ is consumed on the surface by film deposition with $k_{s}$.

For their analytical study, they concluded that a uniform showerhead gas injection (i.e., $S(x)=$ constant) can achieve uniform reactant transport in an isothermal and isobaric system, assuming spatially uniform electron density and energy. Based on this finding, it is inferred that the modification of $S(x)$ can induce the modification of the product distribution. This means that the inlet boundary conditions should be carefully considered in CCP process simulations: in certain cases, it would be necessary to obtain information about the inlet gas distributions separately, as in the work of Kim and Lee. As the showerhead temperature $\left(T_{s h}\right)$ was controlled by the Ohmic heating module in this study, as stated above, the enforced heat flux ensured that the radial uniformities of the gas temperature and density were sufficient along the showerhead radius in the three-dimensional gas flow simulations. In this study, their non-uniformities were less than $3 \%$ with $T_{\text {sh }}=373 \mathrm{~K}$ and less than $6 \%$ with $T_{\text {sh }}=473 \mathrm{~K}$. 
Figure 3 depicts the spatial variations in the gas temperature distributions for Cases 2, 3, 4 and 5. In Figure $3 a-c$, axial variations in the gas temperature distributions, owing to the temperature conditions of the wall, are clearly observed. These variations are attributed to the depletion of the source gas and thus the changing properties of the mixture such as the changes in $\rho_{\text {mix }}$ [27]. However, in Figure $3 d$, because the showerhead temperature and the heater temperature were set to the same value (i.e., $T_{s h}=T_{h}=673 \mathrm{~K}$ ), the temperature distribution is vertically symmetric. Figures 4 and 5 depict the spatial variations in the density distributions of $\mathrm{SiH}_{4}$ and $\mathrm{Si}_{2} \mathrm{H}_{6}$, respectively. We selected $\mathrm{Si}_{2} \mathrm{H}_{6}$ for the analysis because $\mathrm{SiH}_{4}$ is rapidly consumed at gas pressures higher than $100 \mathrm{~Pa}$; thus, $\mathrm{Si}_{2} \mathrm{H}_{6}$ is produced via a fast gas phase reaction between $\mathrm{SiH}_{4}$ and $\mathrm{SiH}_{2}$, as shown below.

$$
\mathrm{SiH}_{4}+\mathrm{SiH}_{2} \rightarrow \mathrm{Si}_{2} \mathrm{H}_{6}, k_{r}=2.0 \times 10^{-16}\left[1-\left(1+0.0032 p_{g}(\mathrm{~Pa})\right)^{-1}\right] \mathrm{m}^{3} \mathrm{~s}^{-1}
$$

Here, $k_{r}$ is the reaction rate coefficient. In addition, $\mathrm{Si}_{2} \mathrm{H}_{6}$ acts as an important seed on which to grow to the high-order silanes, and finally the particles (such as a killer defect).

(a)

\section{Min}

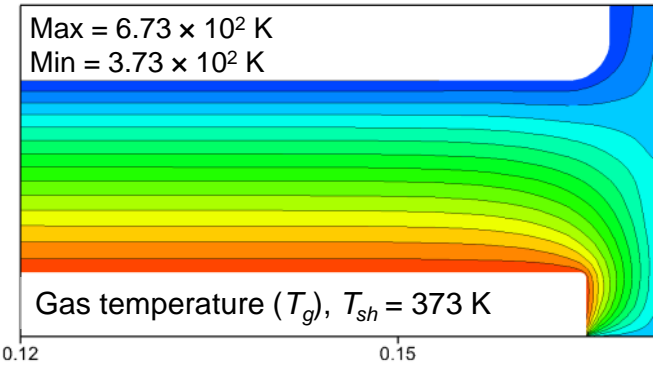

(c)

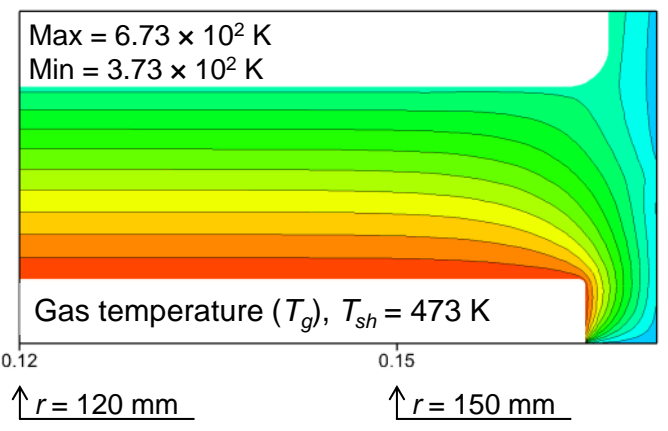

(b)

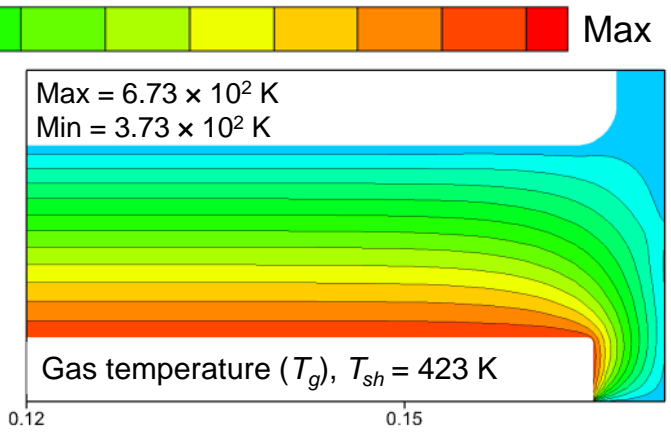

(d)

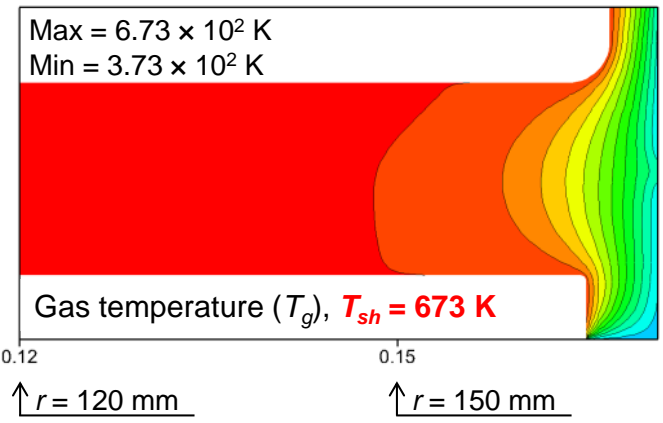

Figure 3. Spatial variations in the gas temperature $\left(T_{g}\right)$ distributions $(\mathrm{K})$ for (a) Case $2\left(T_{\text {sh }}=373 \mathrm{~K}\right)$, (b) Case $3\left(T_{\text {sh }}=423 \mathrm{~K}\right)$, (c) Case $4\left(T_{\text {sh }}=473 \mathrm{~K}\right)$, and $(\mathrm{d})$ Case $5\left(T_{\text {sh }}=673 \mathrm{~K}\right)$ for $r \geq 120 \mathrm{~mm}$. 
(a)

Min

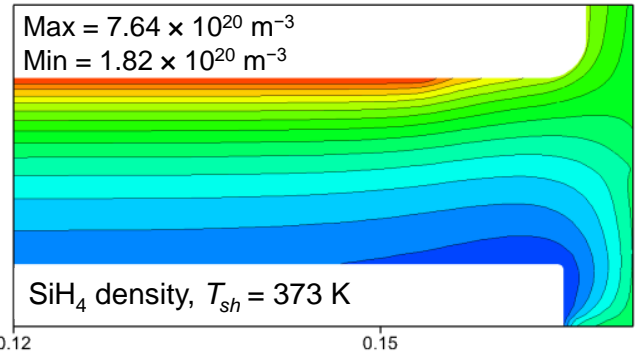

(c)

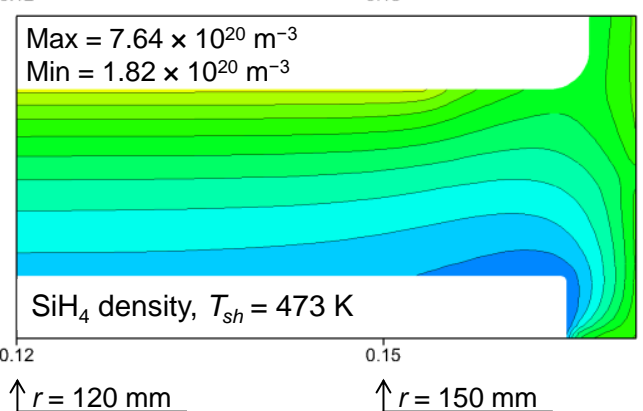

(b)

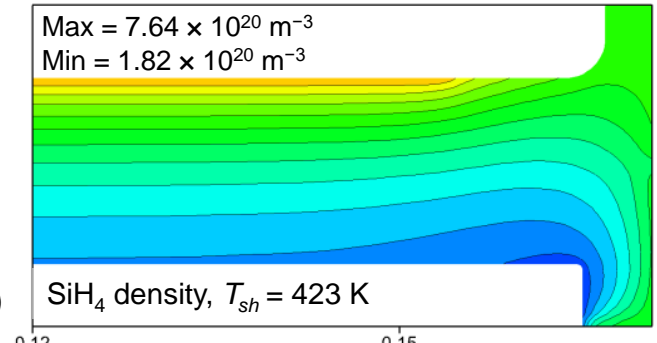

(d)

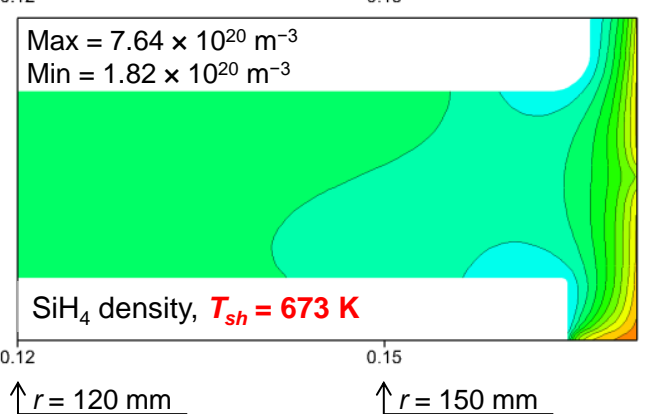

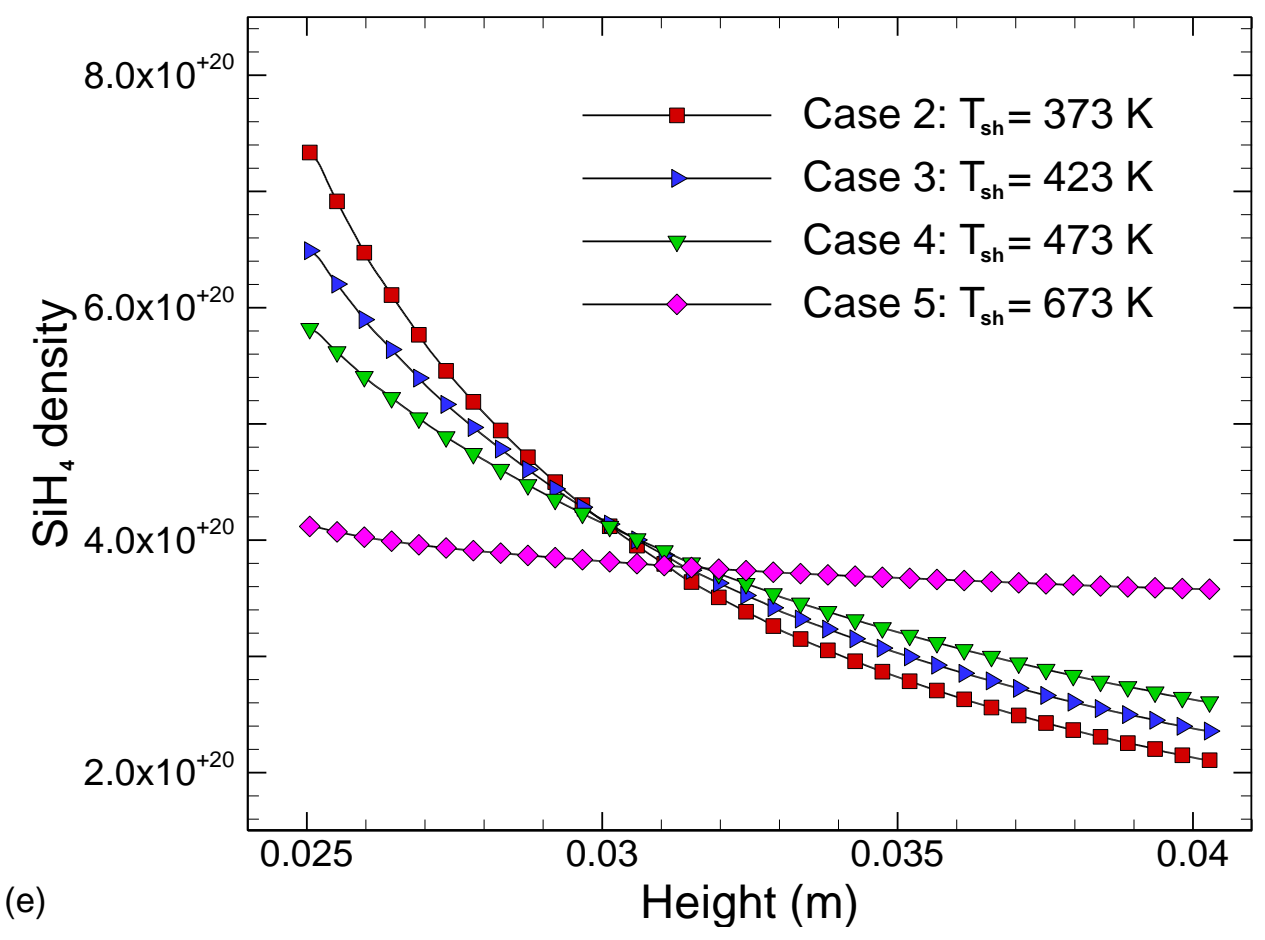

Figure 4. Effects of the showerhead temperature $\left(T_{s h}\right)$ on the spatial distribution of the reactive gas. Spatial variations in the $\mathrm{SiH}_{4}$ density distributions $\left(\mathrm{m}^{-3}\right)$ for $(\mathbf{a})$ Case $2\left(T_{s h}=373 \mathrm{~K}\right)$, (b) Case $3\left(T_{s h}=423 \mathrm{~K}\right)$, (c) Case $4\left(T_{s h}=473 \mathrm{~K}\right)$, and (d) Case 5 $\left(T_{\text {sh }}=673 \mathrm{~K}\right)$ for $r \geq 120 \mathrm{~mm}$. The profiles are radially uniform for $r<120 \mathrm{~mm}$. (e) $\mathrm{SiH}_{4}$ densities are plotted on the vertical line at $r_{h}(r=154.3 \mathrm{~mm})$ for Cases $2,3,4$, and 5 . 
(a)

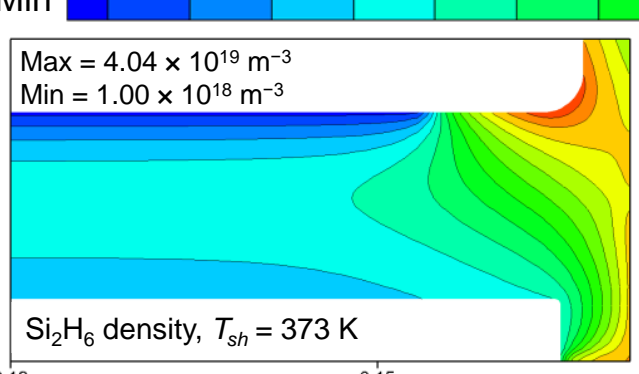

(c)

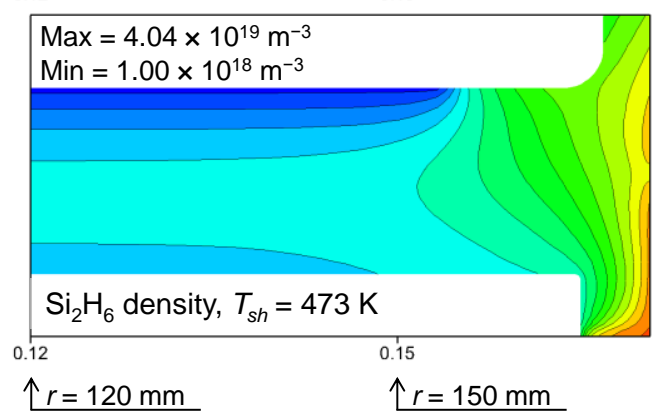

(b)

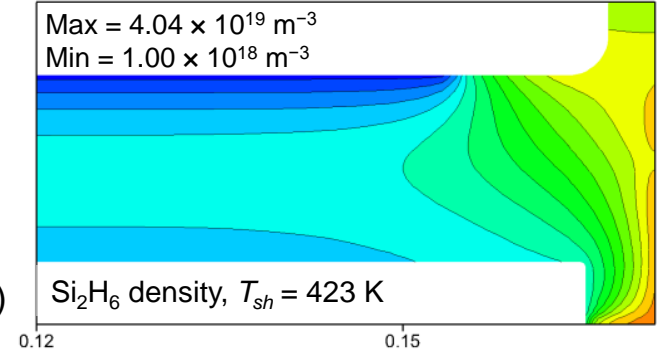

(d)

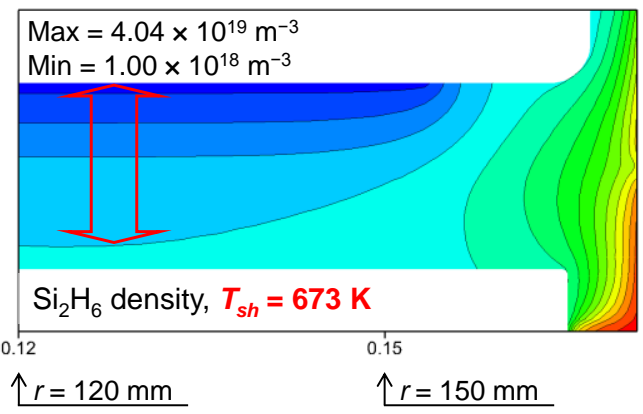

Figure 5. Effects of the showerhead temperature $\left(T_{s h}\right)$ on the spatial distribution of the source gas. Spatial variations in the $\mathrm{Si}_{2} \mathrm{H}_{6}$ density distributions $\left(\mathrm{m}^{-3}\right)$ for $(\mathbf{a})$ Case $2\left(T_{\text {sh }}=373 \mathrm{~K}\right),(\mathbf{b})$ Case $3\left(T_{\text {sh }}=423 \mathrm{~K}\right),(\mathbf{c})$ Case $4\left(T_{\text {sh }}=473 \mathrm{~K}\right)$, and $(\mathbf{d})$ Case $5\left(T_{\text {sh }}=673 \mathrm{~K}\right)$ for $r \geq 120 \mathrm{~mm}$. The profiles are radially uniform for $r<120 \mathrm{~mm}$.

Notably, in various PECVD examples, neutral species can diffuse to the reactor surface rapidly. This efficient transport is expected by the fact that gas kinetic theory states that the diffusion coefficients of neutral species increase under lower pressure conditions. Howling et al. used an $\mathrm{SiH}_{4} / \mathrm{H}_{2}$ mixture to calculate the Peclet number $(\mathrm{Pe}=d \bar{u} / D$, where $d$ is the characteristic length, $\bar{u}$ is the characteristic velocity, and $D$ is the diffusion coefficient) in their CCP process conditions. Taking the binary diffusion coefficient for $\mathrm{SiH}_{4}$ and $\mathrm{H}_{2}$ at $100 \mathrm{~Pa}$ and $473 \mathrm{~K}$ to be $0.14 \mathrm{~m}^{2} \mathrm{~s}^{-1}$, the Pe was calculated as only 0.03 [8]. As our process conditions are similar to those of Howling et al., we confidently assumed that our gas transport phenomena are also observed under conditions of rapid diffusion. We verified that the diffusion coefficients for silicon compounds are sufficiently high under the given process conditions; for example, the diffusion coefficient of $\mathrm{SiH}_{4}$ is $0.057 \mathrm{~m}^{2} \mathrm{~s}^{-1}$ at $673 \mathrm{~K}$. For a characteristic length of $d=0.015 \mathrm{~m}$, a characteristic velocity of $\bar{u}=1.35 \mathrm{~m} \mathrm{~s}^{-1}$, and a diffusion coefficient of $D=0.057 \mathrm{~m}^{2} \mathrm{~s}^{-1}$, the spatially averaged value of $\mathrm{Pe}(\mathrm{Pe}=d \bar{u} / D)$ is calculated to be only 0.36 . Although our Pe is sufficiently low (i.e., less than one), convection effects are still observed in the density distribution contours of $\mathrm{SiH}_{4}$ and $\mathrm{Si}_{2} \mathrm{H}_{6}$.

In Figure 4, for all four cases, in the discharge volume, their $\mathrm{SiH}_{4}$ density distributions have higher values at $r \leq r_{h}$ than at $r>r_{h}$. These variations have their origins in both the source gas consumption routine (based on gas convection) of our showerhead reactor and the transport mechanism resulting from the fast consumption of $\mathrm{SiH}_{4}$. Here, it should be noted that the transport phenomena of neutral species are mainly determined by gas flow streams, which can be described in terms of streamlines. Owing to the common features of the spatial variations in the gas temperature distributions, the spatial variations in the $\mathrm{SiH}_{4}$ density distributions are similar to each other for Cases 2, 3 and 4 . In these three cases, the $\mathrm{SiH}_{4}$ density distributions vary axially in the inter-electrode region, and in addition, radial variations are clearly observed near the electrode edge. The expansion of an ideal gas and the efficient depletion of $\mathrm{SiH}_{4}$ are both responsible for the distribution features. Conversely, in Case 5, the $\mathrm{SiH}_{4}$ density distribution is noticeably changed by the increase in the showerhead temperature. Figure $4 \mathrm{e}$ depicts that the axial variations become negligible in Case 5. Therefore, one can state that in Case 5, an increase in the showerhead temperature significantly modifies the $\mathrm{SiH}_{4}$ density distributions. 
Figure 5 shows that for all four cases, their $\mathrm{Si}_{2} \mathrm{H}_{6}$ densities indicate low values at the inlet (the initial position). However, because of the relatively slow consumption (and fast production) of $\mathrm{Si}_{2} \mathrm{H}_{6}$ and the gas convection effect, its density increases in the axial direction until it reaches the midplane of the discharge volume (i.e., the middle point between the showerhead and the heater). In addition, its density increases in the radial direction until it reaches the sidewall: the depletion of $\mathrm{Si}_{2} \mathrm{H}_{6}$ is not as fast as that of radicals such as $\mathrm{H}, \mathrm{SiH}, \mathrm{SiH}_{2}$, and $\mathrm{SiH}_{3}$ in this study. Note that both the lowest density distribution and the thickest boundary layer occur near the showerhead surface for Case 5.

\subsection{Effects of the Heated Showerhead on Plasma Density Distributions}

Figure 6 depicts the spatial distributions of the ion production rates. To allow for easier comparison, Cases $2\left(T_{s h}=373 \mathrm{~K}\right)$ and $5\left(T_{s h}=673 \mathrm{~K}\right)$ were selected and analyzed more carefully. The production of $\mathrm{SiH}_{2}{ }^{+}$(via direct impact ionization: $\mathrm{e}^{-}+\mathrm{SiH}_{4} \rightarrow \mathrm{SiH}_{2}{ }^{+}+\mathrm{H}$ $+\mathrm{H}+\mathrm{e}^{-}+\mathrm{e}^{-}$) and that of $\mathrm{Si}^{+}$(via dissociative excitation: $\mathrm{He}^{*}+\mathrm{SiH}_{4} \rightarrow \mathrm{Si}^{+}+2 \mathrm{H}+\mathrm{H}_{2}+$ $\mathrm{He}+\mathrm{e}^{-}$) were chosen because of their significance under our conditions. As depicted in Figure $6 \mathrm{a}, \mathrm{b}$, the $\mathrm{SiH}_{2}{ }^{+}$production rates are enhanced near the heater edge. Although the $\mathrm{SiH}_{4}$ density is lower near the showerhead, the $\mathrm{SiH}_{2}{ }^{+}$production rate of Case 5 is higher than that of Case 2. In addition, in Case 5, the axial variation in the $\mathrm{SiH}_{2}{ }^{+}$production rate is bell-shaped, whereas the variation has two maxima in the inter-electrode region in Case 2. The difference in the profiles arises because the higher showerhead temperature lowers the gas density in the immediate surroundings of the showerhead to a sufficient degree, and thus the relative contribution of the mid-plane to the ionization is increased. In Figure $6 c, d$, the rates at which $\mathrm{Si}^{+}$is produced are also enhanced near the heater edge in Cases 2 and 5 . As similarly observed in Figure 6a,b, the axial profile has two maxima in Case 2, whereas the profile is bell-shaped in Case 5. However, the decrease in the $\mathrm{SiH}_{4}$ density as a result of the higher showerhead temperature lowers the $\mathrm{Si}^{+}$production rate in Case 5 relative to that in Case 2 near the showerhead surface. Because He dilution is used in this study, the peak value of the $\mathrm{Si}^{+}$production rate is higher than that of the $\mathrm{SiH}_{2}{ }^{+}$production rate. The rate coefficient for the $\mathrm{Si}^{+}$production used in this study was set as [28]:

$$
\mathrm{He}^{*}+\mathrm{SiH}_{4} \rightarrow \mathrm{Si}^{+}+2 \mathrm{H}+\mathrm{H}_{2}+\mathrm{He}+\mathrm{e}^{-}, k_{r}=1.3 \times 10^{-16} \mathrm{~m}^{3} \mathrm{~s}^{-1} .
$$

(a)

Direct impact ionization rate, $T_{\text {sh }}=373 \mathrm{~K}$ 0.12

(c)

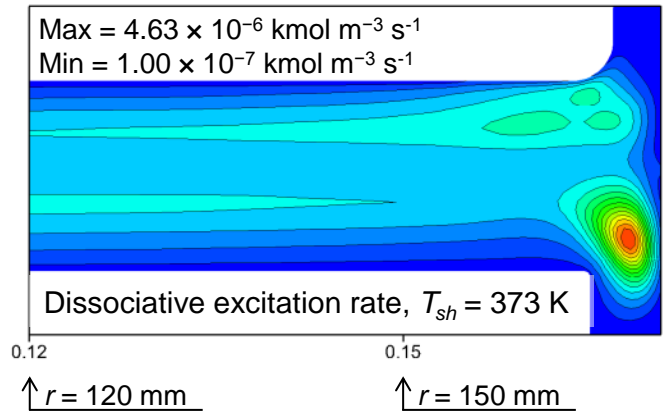

(b)

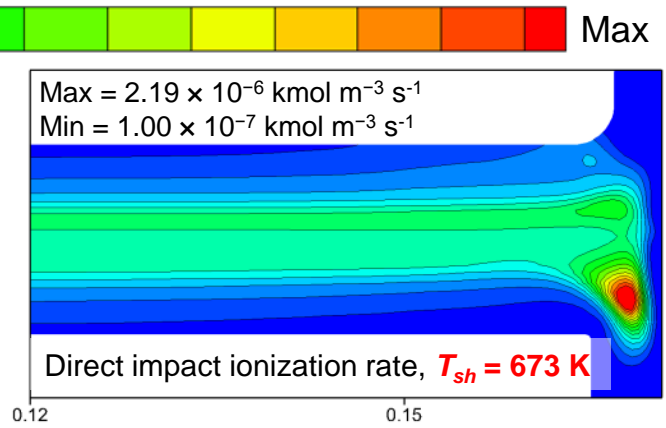

(d)

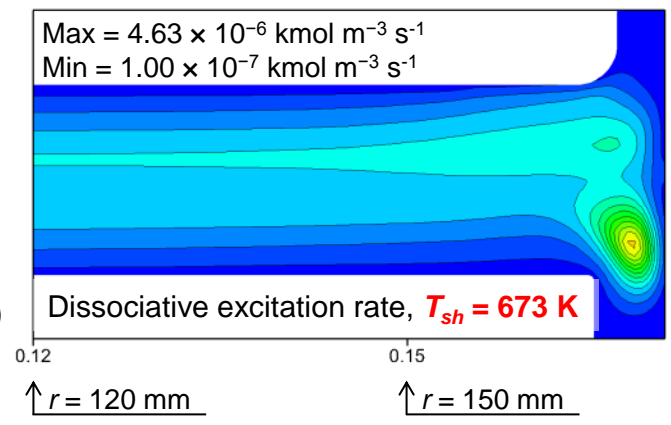

Figure 6. Effects of the showerhead temperature $\left(T_{s h}\right)$ on the spatial distribution of the plasma parameters. Contour plots for the spatial profiles of the time-averaged $\mathrm{SiH}_{2}{ }^{+}$production rate for (a) Case $2\left(T_{s h}=373 \mathrm{~K}\right)$ and $(\mathbf{b})$ Case $5\left(T_{s h}=673 \mathrm{~K}\right)$ 
for $r \geq 120 \mathrm{~mm}$. Contour plots for the spatial profiles of the time-averaged $\mathrm{Si}+$ production rate (c) for Case $2\left(T_{s h}=373 \mathrm{~K}\right)$ and $(\mathrm{d})$ for Case $5\left(T_{s h}=673 \mathrm{~K}\right)$ for $r \geq 120 \mathrm{~mm}$. The profiles are radially uniform for $r<120 \mathrm{~mm}$.

As depicted in Figure 7a,b, the ion production rates in Figure 6 are responsible for the distributions of the time-averaged electron density reaching a maximum near the heater edge: an off-axis maximum of the electron density, $N_{e o}$, is detected at locations similar to the peak ion production rates. As a result of the lower $\mathrm{SiH}_{4}$ density, the peak value of Case 5 is lower than that of Case 2: $N_{e o}$ is $5.90 \times 10^{15} \mathrm{~m}^{-3}$ in Case 2, whereas $N_{e o}$ is $3.93 \times 10^{15} \mathrm{~m}^{-3}$ in Case 5. As shown in Figure 1, the electron power density $\left(P_{e}=-e J_{e} \cdot E, \mathrm{~W} \mathrm{~m}{ }^{-3}\right)$ is also localized near the heater edge. This localization enhances the mean electron energy near the heater edge. Therefore, the locally enhanced production rates mentioned above are strongly correlated with the localization of the electron power density for Cases 2 and 5 , as depicted in Figure 7c,d, respectively. The contours in Figure 7c,d also demonstrate that their peak values are affected by the change in the showerhead temperature.

(a)

\section{Min}

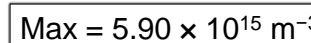

)

Electron density $\left(N_{e}\right), T_{s h}=373 \mathrm{~K}$ 0.12 0.15

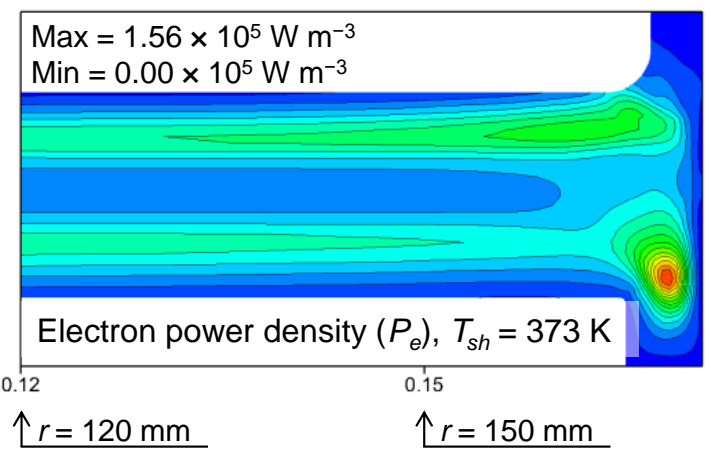

(b)

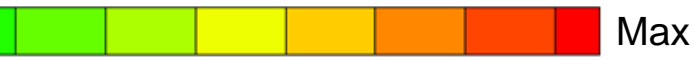

(d)
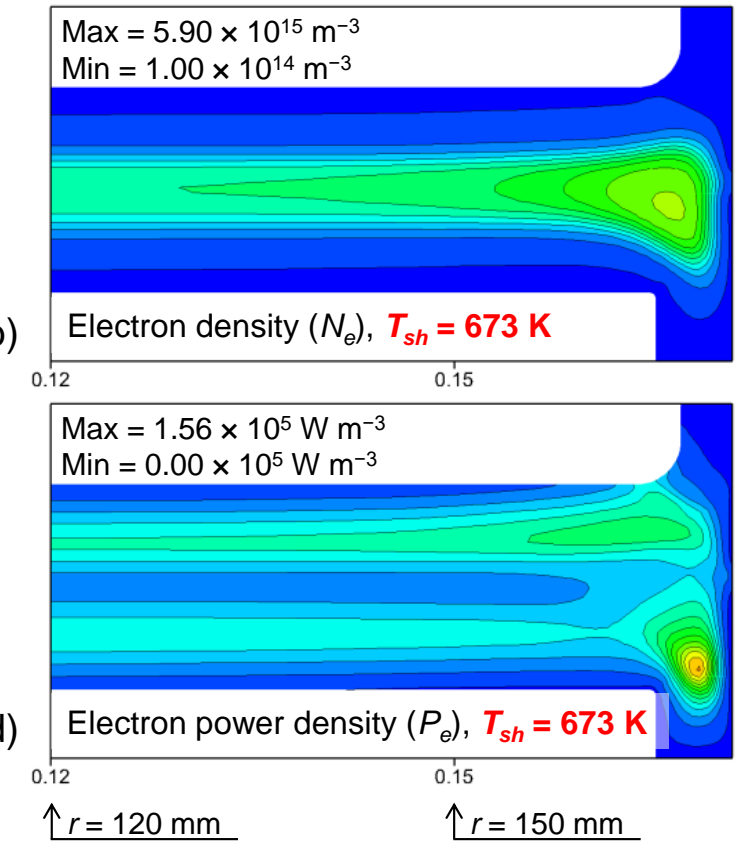

Figure 7. Effects of the showerhead temperature $\left(T_{s h}\right)$ on the spatial distribution of the plasma parameters. Contour plots for the spatial profiles of the time-averaged electron density $\left(N_{e}, \mathrm{~m}^{-3}\right)$ for (a) Case $2\left(T_{s h}=373 \mathrm{~K}\right)$ and (b) Case $5\left(T_{s h}=673 \mathrm{~K}\right)$ for $r \geq 120 \mathrm{~mm}$. Contour plots for the spatial profiles of the time-averaged electron power density $\left(P_{e}, \mathrm{~W} \mathrm{~m}^{-3}\right)$ for $(\mathbf{c})$ Case $2\left(T_{s h}=373 \mathrm{~K}\right)$ and $(\mathbf{d})$ Case $5\left(T_{s h}=673 \mathrm{~K}\right)$ for $r \geq 120 \mathrm{~mm}$. The profiles are radially uniform for $r<120 \mathrm{~mm}$.

\subsection{Effects of the Heated Showerhead on Radical Density Distributions}

Figure 8 provides the contours of the spatial variations in the $\mathrm{SiH}_{3}$ densities $\left(\mathrm{m}^{-3}\right)$ for Cases 2, 3, 4, and 5. $\mathrm{SiH}_{3}$ was selected for analysis from among various other radicals and stable molecules because of its intrinsic importance in the deposition of an a-Si:H film [29]. A common feature between each of the different distributions is that the peak values are detected near the heater edge. 
(a)

Min

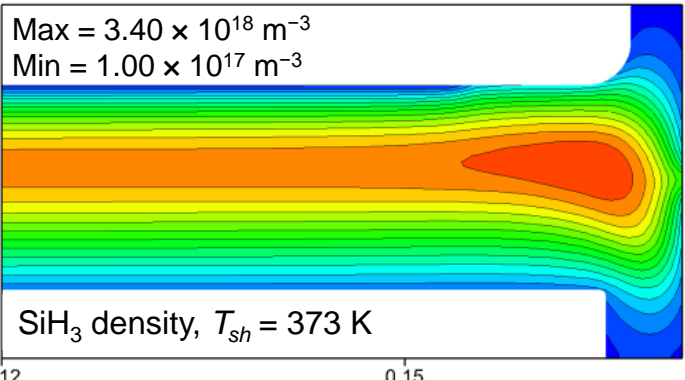

(c)

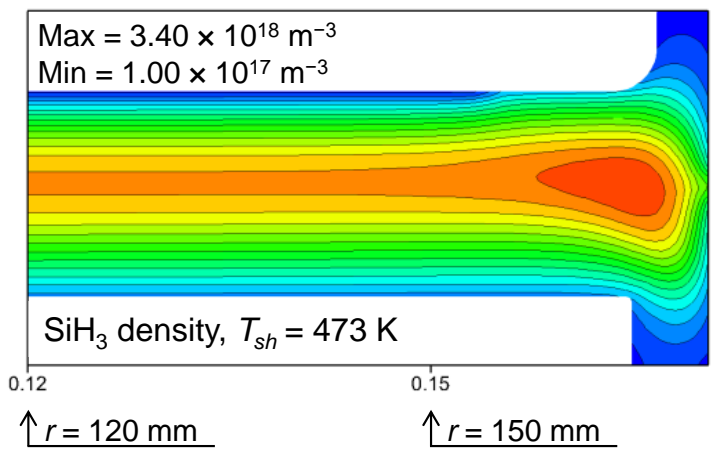

(b)

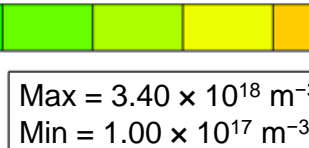

(d)
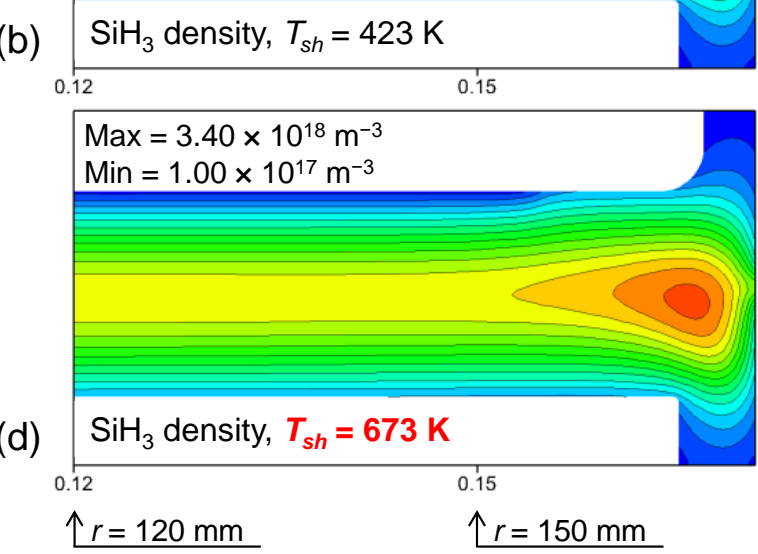

Figure 8. Effects of the showerhead temperature $\left(T_{s h}\right)$ on the spatial distribution of the radical. Spatial variations in the $\mathrm{SiH}_{3}$ density distributions $\left(\mathrm{m}^{-3}\right)$ for $(\mathbf{a})$ Case $2\left(T_{\text {sh }}=373 \mathrm{~K}\right),(\mathbf{b})$ Case $3\left(T_{\text {sh }}=423 \mathrm{~K}\right),(\mathbf{c})$ Case $4\left(T_{\text {sh }}=473 \mathrm{~K}\right)$, and (d) Case 5 $\left(T_{\text {sh }}=673 \mathrm{~K}\right)$ for $r \geq 120 \mathrm{~mm}$. The profiles are radially uniform for $r<120 \mathrm{~mm}$.

In the meantime, although the $\mathrm{SiH}_{3}$ density distributions exhibit higher maximum values with lower showerhead temperature, the values detected near the heater decrease against the expectation, as shown in Figure 8. This behavior can be understood by the $\mathrm{SiH}_{3}$ being quickly depleted in the bulk by the enhancement of the disproportionation process as a result of the higher $\mathrm{SiH}_{3}$ density:

$$
\mathrm{SiH}_{3}+\mathrm{SiH}_{3} \rightarrow \mathrm{SiH}_{2}+\mathrm{SiH}_{4}, k_{r}=1.5 \times 10^{-16} \mathrm{~m}^{3} \mathrm{~s}^{-1}
$$

In addition, $\mathrm{SiH}_{4}$ depletion is suppressed with higher showerhead temperature, as observed in Figures 4 and 5: the maximum $\mathrm{SiH}_{4}$ density of Case $2\left(7.64 \times 10^{20} \mathrm{~m}^{-3}\right)$ becomes higher than that of Case $5\left(7.07 \times 10^{20} \mathrm{~m}^{-3}\right)$, whereas the minimum $\mathrm{SiH}_{4}$ density of Case 2 becomes lower than that of Case 5. As stated above, the same trend was observed for the $\mathrm{SiH}_{3}$ density distribution. The increase in the minimum densities of both $\mathrm{SiH}_{4}$ and $\mathrm{SiH}_{3}$ originates from the higher showerhead temperature suppressing their depletion not only by decreasing the reactant densities in the bulk, but also by decreasing the resistance time. Consequently, the $\mathrm{Si}_{2} \mathrm{H}_{6}$ density decreases as a consequence of the suppressed depletion of $\mathrm{SiH}_{4}\left(\mathrm{SiH}_{4}+\mathrm{SiH}_{2} \rightarrow \mathrm{Si}_{2} \mathrm{H}_{6}\right)$ in Case 5, as shown in Figures 4 and 5. As a result, as depicted in Figure 8, the axial variations in the $\mathrm{SiH}_{3}$ density distributions decrease with the higher showerhead temperature.

\subsection{Effects of the Showerhead Temperature on the Deposition Rate Profile}

Figure 9 shows that for Cases $2\left(T_{\text {sh }}=373 \mathrm{~K}\right), 3\left(T_{\text {sh }}=423 \mathrm{~K}\right), 4\left(T_{\text {sh }}=473 \mathrm{~K}\right), 5$ $\left(T_{s h}=673 \mathrm{~K}\right)$, and 6 , both their deposition rate profiles and averaged rates are affected by the showerhead temperature. For convenience, we compare the spatial features by normalizing the profiles with their corresponding averaged values. 

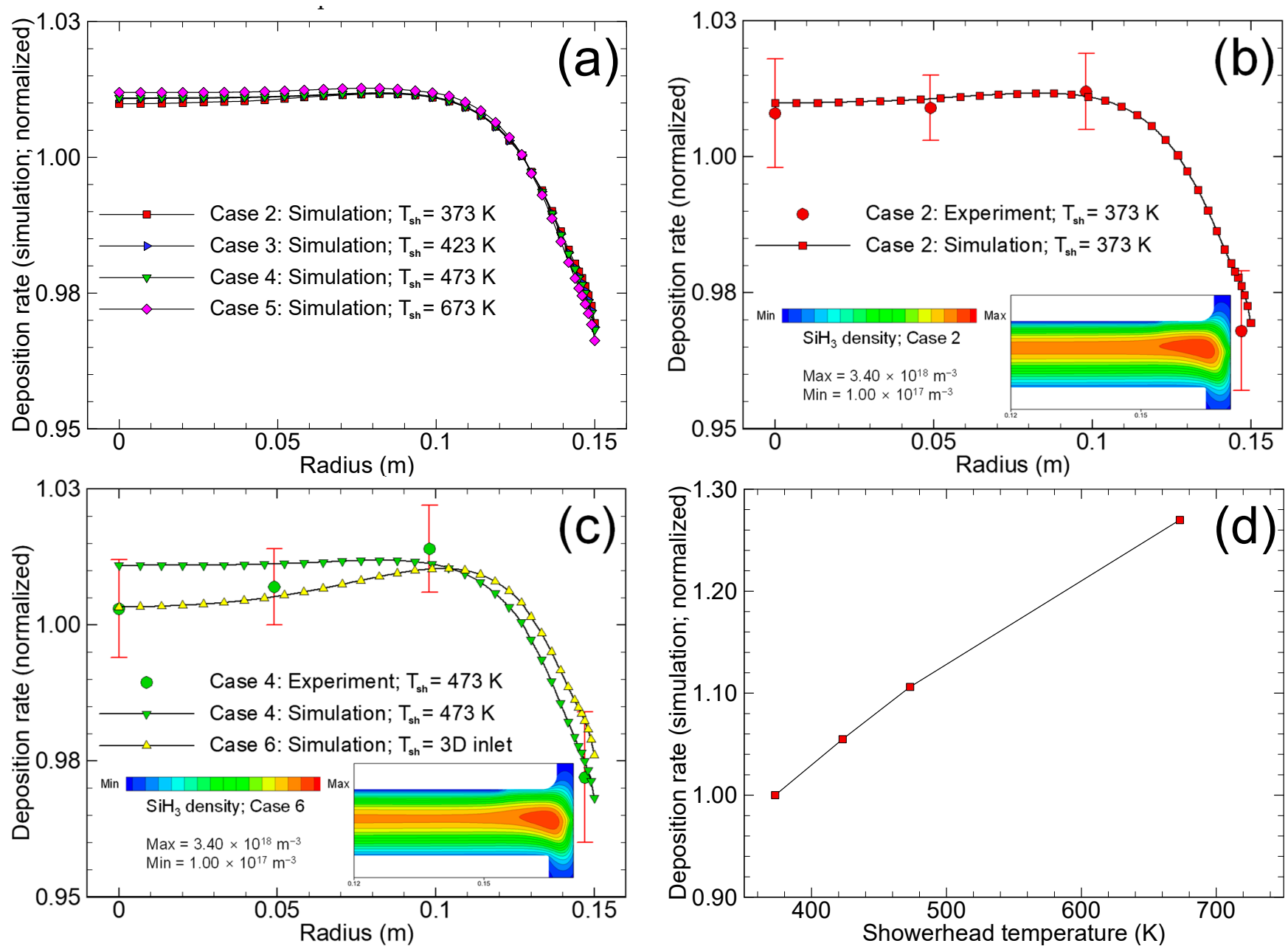

Figure 9. Deposition rates are largely affected by the showerhead temperature. (a) The deposition rate profiles are plotted for Cases $2\left(T_{s h}=373 \mathrm{~K}\right), 3\left(T_{s h}=423 \mathrm{~K}\right), 4\left(T_{s h}=473 \mathrm{~K}\right)$, and $5\left(T_{s h}=673 \mathrm{~K}\right)$. (b) For Case 2, the experimental data are superimposed. (c) For Cases 4 and 6, the experimental data are superimposed. (d) For Cases 2, 3, 4, and 5, the averaged values of the normalized deposition rates are plotted against the showerhead temperature. The experimental data are denoted with larger circle symbols.

For Case 6, we averaged the 3D gas simulation results of the case with $T_{s h}=473 \mathrm{~K}$ (i.e., similarly observed in Case 1) over the azimuthal angle and used the resulting 2D inlet density profile as the input (or the inlet boundary condition) to the 2D plasma simulation. In Figure 9a, the deposition rate profiles are plotted for Cases 2, 3, 4, and 5. For Cases 2 and 4 , their experimental data are superimposed on the profiles in Figure $9 b, c$, respectively. The experimental data are denoted with larger circle symbols. The simulated deposition rate profiles are in good correspondence with the corresponding experimental data.

Note that, because of the modified inlet boundary condition, the simulated deposition rate profile of Case 6 more closely agrees with the corresponding experimental data than that of Case 4, as depicted in Figure 9c. Although the uniformities are different, all the profiles are convex. As depicted in Figure 8, the boundary layers of the $\mathrm{SiH}_{3}$ density thicken, approaching $r=150 \mathrm{~mm}$; the thicknesses of the boundary layers tend to decrease slightly, further approaching each other near the heater edge (at $r=165 \mathrm{~mm}$ ). The lower $\mathrm{SiH}_{3}$ surface fluxes result in the boundary layers of the $\mathrm{SiH}_{3}$ density field becoming thicker; thus, the deposition rates decrease in the vicinity of $r=150 \mathrm{~mm}$. At the heater edge, the origin of the higher $\mathrm{SiH}_{3}$ surface flux can be understood by the electron-impact dissociation being enhanced by the $N_{e o}$ there, and thus excess $\mathrm{SiH}_{3}$ is produced and transported to the heater surface. 
In Figure 9d, for Cases 2, 3, 4, and 5, the averaged values of the normalized deposition rates are plotted against the showerhead temperature. The values are normalized with the average value of Case 2 for the clear comparison. Notably, the average rates are largely affected by the showerhead temperature: the average deposition rate of Case 5 is approximately 30\% higher than that of Case 2, although the maximum value of the $\mathrm{SiH}_{3}$ density of Case 5 is lower than that of Case 2. The increase in the deposition rate can be understood by observing the increase in the $\mathrm{SiH}_{3}$ density near the heater surface in Figure 8 .

\subsection{Effects of the Showerhead Temperature on the Particle Deposition}

To analyze the effects of increasing the temperature of the showerhead on lowering the number of particles transported onto the heater surface, the number of particles that were deposited was experimentally measured by counting the total number of particles. The input parameters were identical to those of Cases 2, 3, 4, and 5. In Figure 10, the number of particles of which the size is characteristically larger than $45 \mathrm{~nm}$ is plotted against the showerhead temperature: in the inset, simulation results of $\mathrm{Si}_{2} \mathrm{H}_{6}$ density distributions are depicted for Cases 2 and 5. The higher showerhead temperature decreases the number of deposited particles. Note that the number of particles of which the size exceeds $45 \mathrm{~nm}$ is decreased by approximately $93 \%$ by increasing the showerhead temperature from 373 to $553 \mathrm{~K}$.

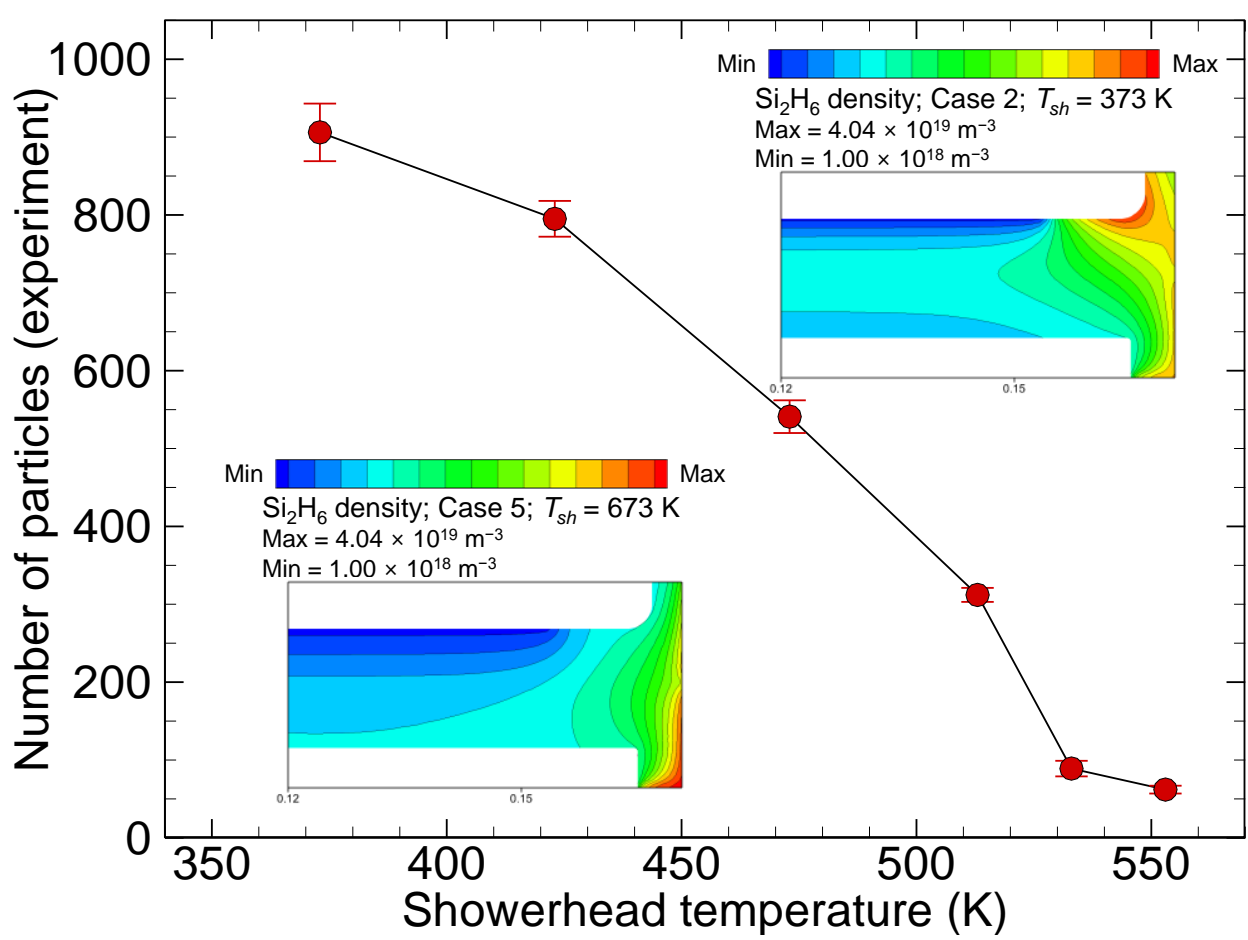

Figure 10. Effects of the showerhead temperature on the number of particles deposited on the heater surface. The number of deposited particles is plotted against the showerhead temperature.

Understanding the tendency of the number of particles to decrease, as depicted in Figure 10, would require us to analyze the effects of the heated showerhead on the spatial distributions of the high-order silanes such as $\mathrm{Si}_{n} \mathrm{H}_{2 n+2}(n \geq 5)$. Figures 11 and 12 demonstrate that for Cases 2, 3, 4, and 5, $\mathrm{Si}_{5} \mathrm{H}_{12}$ and $\mathrm{Si}_{12} \mathrm{H}_{26}$ reach the heater surface less easily when the showerhead temperature is higher, respectively. The thickness of the diffusion layer formed near the showerhead inlet becomes slightly larger with higher showerhead temperature, regardless of the value of $n$ in the high-order silane. As a result of the slower growth, the compositions of these species are lowered at the heater surface. 


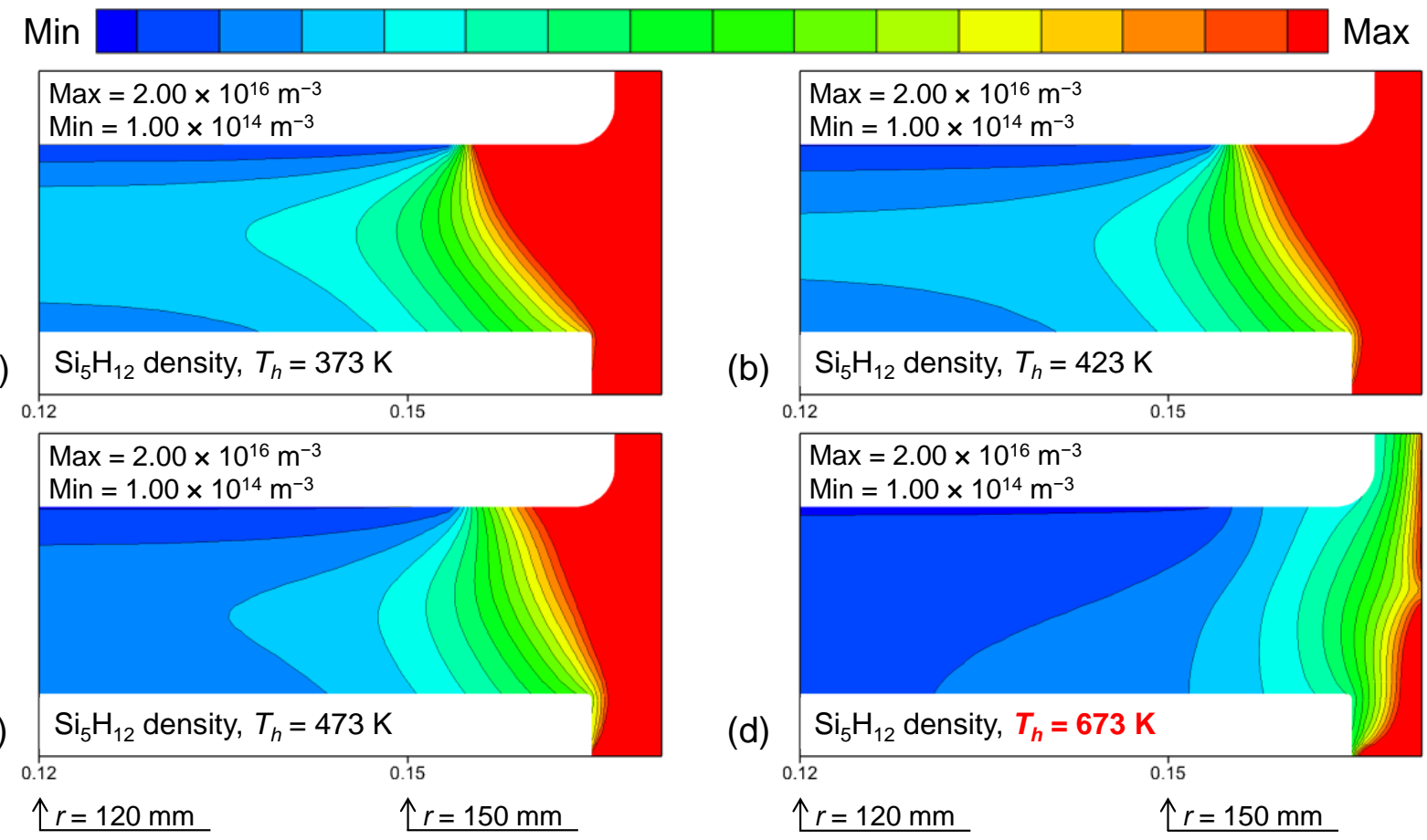

Figure 11. Effects of the showerhead temperature $\left(T_{s h}\right)$ on the spatial distribution of high-order silanes. Spatial variations in the $\mathrm{Si}_{5} \mathrm{H}_{12}$ density distributions $\left(\mathrm{m}^{-3}\right)$ for $(\mathbf{a})$ Case $2\left(T_{s h}=373 \mathrm{~K}\right)$, (b) Case $3\left(T_{s h}=423 \mathrm{~K}\right)$, (c) Case $4\left(T_{s h}=473 \mathrm{~K}\right)$, and (d) Case $5\left(T_{s h}=673 \mathrm{~K}\right)$.

(a)

\section{Min}

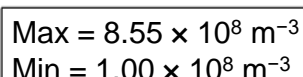

$\mathrm{Si}_{12} \mathrm{H}_{26}$ density, $T_{h}=373 \mathrm{~K}$

0.12

$\operatorname{Max}=8.55 \times 10^{8} \mathrm{~m}^{-3}$

Min $=1.00 \times 10^{8} \mathrm{~m}^{-3}$

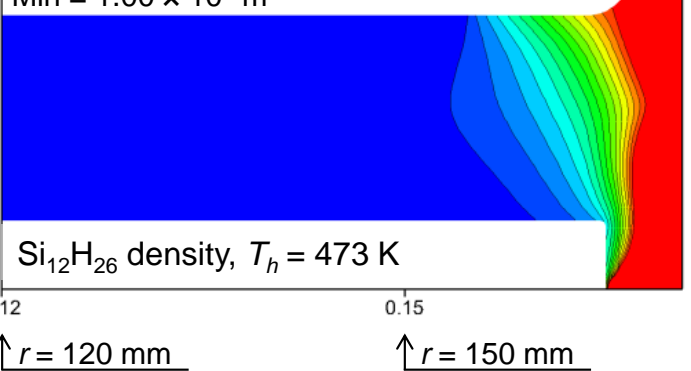

(b)

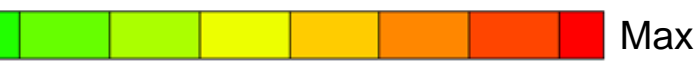

(d)

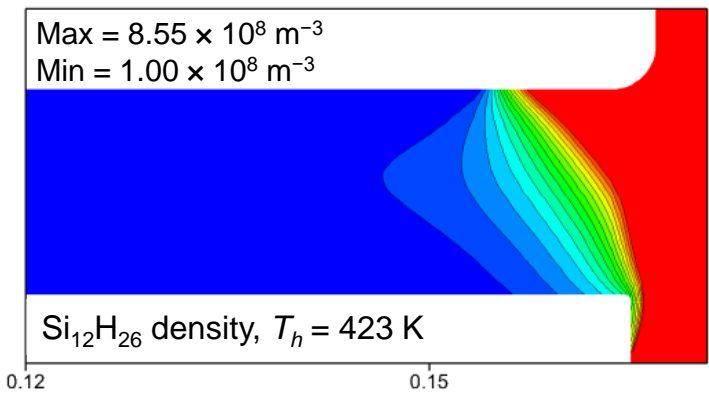

$\operatorname{Max}=8.55 \times 10^{8} \mathrm{~m}^{-3}$

Min $=1.00 \times 10^{8} \mathrm{~m}^{-3}$

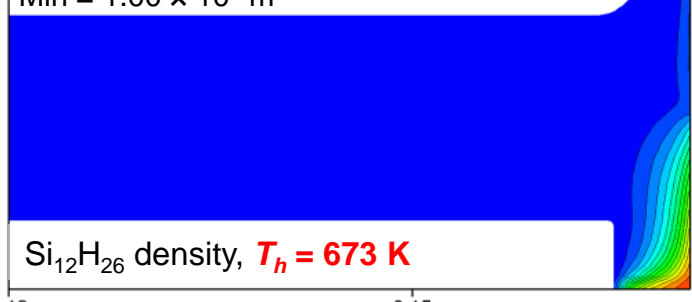

$\uparrow r=120 \mathrm{~mm} \quad 0.15$

Figure 12. Effects of the showerhead temperature $\left(T_{s h}\right)$ on the spatial distribution of high-order silanes. Spatial variations in the $\mathrm{Si}_{12} \mathrm{H}_{26}$ density distributions $\left(\mathrm{m}^{-3}\right)$ for $(\mathbf{a})$ Case $2\left(T_{\text {sh }}=373 \mathrm{~K}\right),(\mathbf{b})$ Case $3\left(T_{\text {sh }}=423 \mathrm{~K}\right),(\mathbf{c})$ Case $4\left(T_{\text {sh }}=473 \mathrm{~K}\right)$, and (d) Case $5\left(T_{\text {sh }}=673 \mathrm{~K}\right)$.

As similarly observed in Figure $5\left(\mathrm{Si}_{2} \mathrm{H}_{6}\right)$, in all four cases, the density distribution of $\mathrm{Si}_{5} \mathrm{H}_{12}$ is initially low at the showerhead inlet and increases as it approaches the bulk plasma region in Figure 11. Case 5 has the lowest density distribution of $\mathrm{Si}_{5} \mathrm{H}_{12}$ near the 
heater surface. This similar growth trend originates from $\mathrm{Si}_{5} \mathrm{H}_{12}$ being grown from $\mathrm{Si}_{2} \mathrm{H}_{6}$ by cluster formation as a result of $\mathrm{SiH}_{2}$ insertion, as shown below:

$$
\mathrm{SiH}_{2}+\mathrm{Si}_{n} \mathrm{H}_{2 n+2} \rightarrow \mathrm{Si}_{n+1} \mathrm{H}_{2 n+4}, k_{r}=4.2 \times 10^{-16}\left[1-\left(1+0.0033 p_{g}(\mathrm{~Pa})\right)^{-1}\right] \mathrm{m}^{3} \mathrm{~s}^{-1},
$$

where $n$ is larger than one [9]. As $\mathrm{Si}_{12} \mathrm{H}_{26}$ is also generated from the above $\mathrm{SiH}_{2}$ insertion reaction, the difference in the $\mathrm{Si}_{12} \mathrm{H}_{26}$ density distribution between Cases 2 and 5 increases, as shown in Figure 12 (note that the observed difference is two orders of magnitude).

\section{Conclusions}

In this study, we investigated how to enhance the cleanliness and deposition rate by aiming to understand the multiple roles of the showerhead electrode in a CCP reactor. The discharge volume was installed between the showerhead electrode and the heater electrode. We simulated the gas transport in a three-dimensional complex geometry, whereas the $\mathrm{SiH}_{4} / \mathrm{He} \mathrm{CCP}$ discharges were considered in a simplified two-dimensional geometry.

The $\mathrm{SiH}_{4} / \mathrm{He}$ discharges were investigated by varying the showerhead temperature $T_{s h}$ as $373,423,473$, and $673 \mathrm{~K}$. The simulation results were validated through comparison with a practical PECVD experiment. We analyzed the extent to which the heated showerhead was able to contribute to increasing the deposition rate as well as to decreasing the number of particles generated during plasma processes. A comparison between Cases 2 $\left(T_{s h}=373 \mathrm{~K}\right)$ and $5\left(T_{s h}=673 \mathrm{~K}\right)$ showed that the $\mathrm{Si}^{+}$production rate in Case 5 was lower than that in Case 2 as a result of the decreased $\mathrm{SiH}_{4}$ density near the hotter showerhead.

Although the peak electron density was lower near the electrode edge in Case 5 compared to Case 2, the $\mathrm{SiH}_{3}$ density detected near the heater increased in Case 5. This comparison can be understood by $\mathrm{SiH}_{3}$ being depleted faster in the bulk by the enhancement in the disproportionation process as a result of the higher peak $\mathrm{SiH}_{3}$ density in Case 2. As a result, the average deposition rate of Case 5 was approximately $30 \%$ higher than that of Case 2. The effect of increasing the showerhead temperature on decreasing the number of particles transported onto the heater was experimentally measured by counting the number of particles that were deposited. The number of particles larger than $45 \mathrm{~nm}$ was decreased by approximately $93 \%$ by increasing the showerhead temperature from 373 to $553 \mathrm{~K}$.

Funding: This work was supported by the Gachon University research fund of 2019 (GCU-2019-0814) and the National Research Council of Science \& Technology (NST) grant by the Korea government (MSIT) (No. CRC-20-01-NFRI).

Institutional Review Board Statement: Not applicable.

Informed Consent Statement: Not applicable.

Data Availability Statement: Not applicable.

Conflicts of Interest: The authors declare no conflict of interest.

\section{References}

1. Smith, D.L. Thin-Film Deposition: Principles and Practice; McGraw-Hill: New York, NY, USA, 1995.

2. Lieberman, M.A.; Lichtenberg, A.J. Principles of Plasma Discharges and Materials Processing; John Wiley \& Sons Inc.: Hoboken, NJ, USA, 2005.

3. Maydan, D. The future of equipment development and semiconductor production. Mater. Sci. Eng. A 2001, 302, 1-5. [CrossRef]

4. Yavas, O.; Richter, E.; Kluthe, C.; Sickmoeller, M. Wafer-edge yield engineering in leading-edge DRAM manufacturing. Semicond. Fabtech 2009, 39, 1-5.

5. Hwang, S.; Kanarik, K. Evolution of Across-Wafer Uniformity Control in Plasma Etch. Available online: https://sst. semiconductor-digest.com/2016/08/evolution-of-across-wafer-uniformity-control-in-plasma-etch/ (accessed on 1 August 2021).

6. Sansonnens, L.; Howling, A.A.; Hollenstein, C. A gas flow uniformity study in large-area showerhead reactors for RF plasma deposition. Plasma Sources Sci. Technol. 2000, 9, 205-209. [CrossRef] 
7. Leroy, O.; Gousset, G.; Alves, L.L.; Perrin, J.; Jolly, J. Two-dimensional modelling of SiH4-H2 radio-frequency discharges for a-Si:H deposition. Plasma Sources Sci. Technol. 1998, 7, 348. [CrossRef]

8. Howling, A.A.; Legradic, B.; Chesaux, M.; Hollenstein, C. Plasma deposition in an ideal showerhead reactor: A two-dimensional analytical solution. Plasma Sources Sci. Technol. 2012, 21, 535-542. [CrossRef]

9. Perrin, J.; Leroy, O.; Bordage, M.C. Cross-sections, rate constants and transport coefficients in silane plasma chemistry. Contrib. Plasma Phys. 1996, 36, 3-49. [CrossRef]

10. Lee, S.; Won, J.; Choi, J.; Jang, S.; Jee, Y.; Lee, H.; Byun, D. Preparation and analysis of amorphous carbon films deposited from $\left(\mathrm{C}_{6} \mathrm{H}_{12}\right) / \mathrm{Ar} / \mathrm{He}$ chemistry for application as the dry etch hard mask in the semiconductor manufacturing process. Thin Solid Films 2011, 519, 6737-6740. [CrossRef]

11. Lee, S.; Won, J.; Choi, J.; Park, J.; Jee, Y.; Lee, H.; Byun, D. Comparative study on the properties of amorphous carbon layers deposited from 1-hexene and propylene for dry etch hard mask application in semiconductor device manufacturing. Thin Solid Films 2011, 519, 6683-6687. [CrossRef]

12. Lee, S.M.; Won, J.; Yim, S.; Park, S.J.; Choi, J.; Kim, J.; Lee, H.; Byun, D. Effect of deposition temperature and thermal annealing on the dry etch rate of a-C:H films for the dry etch hard process of semiconductor devices. Thin Solid Films 2012, 520, 5284-5288. [CrossRef]

13. Denpoh, K.; Moroz, P.; Kato, T.; Matsukuma, M. Multiscale plasma and feature profile simulations of plasma-enhanced chemical vapor deposition and atomic layer deposition processes for titanium thin film fabrication. Jpn. J. Appl. Phys. 2020, 59, SHHB02. [CrossRef]

14. Kim, H.J.; Lee, H.J. Analysis of intermediate pressure SiH4/He capacitively coupled plasma for deposition of an amorphous hydrogenated silicon film in consideration of thermal diffusion effects. Plasma Sources Sci. Technol. 2017, 26, 085003. [CrossRef]

15. Kim, H.J.; Lee, H.J. Uniformity control of the deposition rate profile of a-Si:H film by gas velocity and temperature distributions in a capacitively coupled plasma reactor. J. Appl. Phys. 2018, 123, 113302. [CrossRef]

16. Kleijn, C.R.; Meer, T.H.v.d.; Hoogendoorn, C.J. A mathematical model for LPCVD in a single wafer reactor. J. Electrochem. Soc. 1989, 136, 3423. [CrossRef]

17. Kleijn, C.R.; Hoogendoorn, C.J.; Hasper, A.; Holleman, J.; Middelhoek, J. Transport phenomena in tungsten LPCVD in a single-wafer reactor. J. Electrochem. Soc. 1991, 138, 509. [CrossRef]

18. CFD, R.C. CFD-ACE Module Manual; ESI US R\&D Inc.: Huntsville, AL, USA, 2003.

19. Farouk, T.; Farouk, B.; Staack, D.; Gutsol, A.; Fridman, A. Simulation of dc atmospheric pressure argon micro glow-discharge. Plasma Sources Sci. Technol. 2006, 15, 676-688. [CrossRef]

20. Farouk, T.; Farouk, B.; Gutsol, A.; Fridman, A. Atmospheric pressure methane-hydrogen dc micro-glow discharge for thin film deposition. J. Phys. D Appl. Phys. 2008, 41, 175202. [CrossRef]

21. Kim, H.J.; Lee, H.J. 2D fluid model analysis for the effect of 3D gas flow on a capacitively coupled plasma deposition reactor. Plasma Sources Sci. Technol. 2016, 25, 035006. [CrossRef]

22. Kim, H.J.; Beskok, A. An algebraic factorisation scheme for spectral element solution of incompressible flow and scalar transport. Int. J. Comp. Fluid Dynamics 2010, 24, 95-108. [CrossRef]

23. Lee, A.S.; Rajagopalan, N.; Le, M.; Kim, B.H.; M'Saad, H. Development and characterization of a PECVD silicon nitride for damascene applications. J. Electrochem. Soc. 2004, 151, F7-F9. [CrossRef]

24. Kim, J.-H.; Moon, S.; Kim, J.-W.; Lee, D.; Park, B.C.; Kim, D.-H.; Jeong, Y.; Hand, S.; Osborne, J.; Wolf, P.D.; et al. Advanced measurement and diagnosis of the effect on the underlayer roughness for industrial standard metrology. Sci. Rep. 2019, 9, 1018. [CrossRef]

25. Perrin, J.; Shiratani, M.; Kae-Nune, P.; Videlot, H.; Jolly, J.; Guillon, J. Surface reaction probabilities and kinetics of $\mathrm{H}_{2} \mathrm{SiH}_{3}, \mathrm{Si}_{2} \mathrm{H}_{5}$ $\mathrm{CH}_{3}$, and $\mathrm{C}_{2} \mathrm{H}_{5}$ during deposition of a-Si:H and a-C:H from $\mathrm{H}_{2}, \mathrm{SiH}_{4}$, and $\mathrm{CH}_{4}$ discharges. J. Vac. Sci. Technol. A. 1998, 16, 278. [CrossRef]

26. Danko, S.; Bluhm, D.; Bolsinger, V.; Dobrygin, W.; Schmidt, O.; Brinkmann, R.P. A global model study of silane/hydrogen discharges. Plasma Sources Sci. Technol. 2013, 22, 055009. [CrossRef]

27. Bird, R.B.; Stewart, W.E.; Lightfoot, E.N. Transport Phenomena; John Wiley \& Sons, Inc.: Hoboken, NJ, USA, 2007.

28. Kushner, M.J. Simulation of the gas-phase processes in remote-plasma-activated chemical-vapor deposition of silicon dielectrics using rare gas-silane-ammonia mixtures. J. Appl. Phys. 1992, 9, 4173-4189. [CrossRef]

29. Park, H.; Yoon, E.; Lee, G.-D.; Kim, H.J. Analysis of surface adsorption kinetics of $\mathrm{SiH} 4$ and $\mathrm{Si}_{2} \mathrm{H}_{6}$ for deposition of a hydrogenated silicon thin film using intermediate pressure $\mathrm{SiH}_{4}$ plasmas. Appl. Surf. Sci. 2019, 496, 143728. [CrossRef] 